\title{
BMJ Open Impact of the COVID-19 pandemic on the experience and mental health of university students studying in Canada and the UK: a cross-sectional study
}

\author{
Jennifer A Appleby (D) ," Nathan King (D) , ${ }^{2}$ Kate E Saunders, ${ }^{3,4}$ Anne Bast, ${ }^{1}$ \\ Daniel Rivera (D) ${ }^{5}$ Jin Byun, ${ }^{6}$ Simone Cunningham, ${ }^{7}$ Charandeep Khera, ${ }^{3}$ \\ Anne C Duffy (1) ${ }^{3,8}$
}

To cite: Appleby JA, King N, Saunders KE, et al. Impact of the COVID-19 pandemic on the experience and mental health of university students studying in Canada and the UK: a crosssectional study. BMJ Open 2022;12:e050187. doi:10.1136/ bmjopen-2021-050187

- Prepublication history and additional supplemental material for this paper are available online. To view these files, please visit the journal online (http://dx.doi.org/10.1136/ bmjopen-2021-050187)

Received 13 February 2021 Accepted 04 January 2022

Check for updates

(C) Author(s) (or their employer(s)) 2022. Re-use permitted under CC BY-NC. No commercial re-use. See rights and permissions. Published by BMJ.

For numbered affiliations see end of article.

Correspondence to

Dr Anne C Duffy;

anne.duffy@queensu.ca

\section{ABSTRACT}

Objectives To explore the impact of the COVID-19 pandemic on the experiences and mental health of university students.

Design A cross-sectional study consisting of an electronic survey about students' experiences and concerns during the pandemic and the associated impact. In addition to the quantitative analysis, free-text responses were extracted and analysed using a framework technique.

Setting Queen's University in Canada and the University of Oxford in the UK.

Participants Undergraduate students at Queen's University and first-year undergraduate students at the University of Oxford were invited to complete the COVID-19 supplement survey. This study included data from 3013 Queen's students as the primary focus and 339 0xford students as a secondary comparison.

Results Females at Queen's reported greater adherence to government recommendations to prevent the spread of COVID-19 (91.3\% vs $\left.86.7 \%, \chi^{2} p<0.01\right)$ and were more likely to self-isolate $\left(63.9 \%\right.$ vs $\left.57.0 \%, \chi^{2} p<0.01\right)$ than males. A similar trend was seen among 0xford students. Students' concerns were wide ranging including those related to their learning experience, finances and future academic and career prospects. 78.9\% of Queen's students and $50.4 \%$ of first-year 0xford students reported worries about the long-term impact on their academic and job prospects. A sizeable proportion of students also reported that the pandemic negatively impacted their plans to continue at university $(29.4 \%$ of Queen's, $14.2 \%$ of Oxford) and disrupted activities important to their mental well-being. Key themes identified in the qualitative component included the negative impacts of social isolation, challenging academic changes and disruption to support services and means of coping.

Conclusions Overall, findings underscore the importance of addressing areas of student concern and the aspects of student life negatively impacted by the pandemic in order to maintain student well-being and support a successful university experience.

\section{INTRODUCTION}

In late 2019, COVID-19 was detected in Wuhan, China, causing disease ranging from
Strengths and limitations of this study

- The first study to compare the impact of the COVID-19 pandemic on university students across different countries.

- Responses were obtained from large, diverse samples of university students.

- Validated measures were used to assess the impact of the pandemic on students.

- A low response rate was obtained from the Queen's University sample.

- Participants were surveyed early in the pandemic, and the impact on students may change over time.

asymptomatic infection to life-threatening respiratory compromise. ${ }^{1}$ The restrictions imposed to limit viral transmission and the direct impact of the virus profoundly affected daily life and well-being, with heightened anxiety and reduced access to usual coping mechanisms including exercise, socialisation and leisure activities. ${ }^{2}$

University students have been particularly affected by COVID-19. Remote teaching and social distancing measures implemented across institutions worldwide have dramatically changed campus life. ${ }^{3}$ In addition to the changes experienced by the general population, students have experienced disruption to their learning, assessment and schedules, and the cancellation of enriched learning opportunities including field trips, laboratory courses and learning exchanges. Additionally, the pandemic may affect future educational opportunities, job prospects and financial stability.

The pandemic and its aftermath will likely have lasting effects on students and universities. Therefore, there is a need for the collection of reliable data to assess the impact of the pandemic on student well-being and 
academic outcomes. This would improve our understanding of student experiences and concerns, informing institutions' approaches to addressing these.

In this study, we aimed to explore university student experiences during the COVID-19 pandemic, including concerns related to the pandemic and the associated impact on education, daily life, career prospects and mental health support. We leveraged an ongoing longitudinal survey study of undergraduate students attending Queen's University in Canada and the University of Oxford in the UK. ${ }^{45}$

\section{METHODS}

COVID-19 specific measures were added to the ongoing U-Flourish Student Well-Being and Academic Success survey, ${ }^{6}$ which invites first-year university students at Queen's (Canada) and Oxford (UK) to complete electronic surveys at the beginning and end of each academic year. The surveys ask about risk and protective factors for well-being and mental health using validated measures. COVID-19 related questions were added to the U-Flourish follow-up survey for participating first-year Oxford students (May 2020) and sent out as a supplementary survey to all registered Queen's undergraduate students (July 2020).

\section{Study variables}

Demographic characteristics

Age in years and gender were self-reported and international student status, and programme and year of study were obtained from university administrative data.

\section{COVID-19 related measures}

Queen's participants were asked to describe their approach to self-isolation during the pandemic by selecting all options that applied from a list of nine options, grouped into: (1) no change (i.e., 'I have lived my life as normal'), (2) minor change, but not self-isolation (e.g., social distancing and working from home) and (3) self-isolation (i.e., staying at home and avoiding contact with people outside of your household). Participants rated their knowledge level on COVID-19 from ' 1 - very poor' to ' 7 - very good' and whether they have been following government recommendations from ' 1 - Not at all' to '7 - Very much so'.

At both Queen's and Oxford, anxiety surrounding the pandemic was assessed using the COVID-19 Pandemic Anxiety Scale. ${ }^{7}$ A series of nine statements asked how serious an issue do you think COVID-19 is and how worried are you about the following: catching COVID-19, friends and family catching COVID-19, leaving the house, infecting others, having enough food and other essential items, missing university and the impact on your finances and long-term academic and job prospects. Each statement was rated on a five-point scale according to level of agreement, recategorised into 'disagree' (1-2), 'neither disagree or agree' (3) and 'agree' (4-5).

Students were also asked about the impact of the pandemic on their studies and learning opportunities, future academic/professional prospects, lifestyle, relationships and connectedness and, for those in need, access to mental health support. Participants rated the impact of the pandemic and associated social distancing on a five-point scale from $1=$ very negative to 5 =very positive (categorised into 'negative', 'neither', or 'positive'). On the Oxford survey, 7 of the 13 impact items were included. Participants were asked if any mental health support they receive had been stopped, postponed or negatively affected due to the pandemic.

Finally, participants were asked, 'Are there any other significant impacts related to the COVID-19 pandemic on your mental health, wellbeing, or education that you would like to comment on?'.

\section{Statistical analysis}

The primary analysis used data from the Queen's COVID-19 survey. Responses to the Pandemic Anxiety Scale and questions assessing the impact of the pandemic and associated social distancing were examined in the Oxford sample in an exploratory manner to compare between institutions and countries. Samples were restricted to participants with complete data on the variables of interest. Analyses were conducted using RStudio. ${ }^{8}$ Descriptive statistics were used to describe the sample, and responses to the Pandemic Anxiety Scale and COVID-19 impact items overall and by gender, age group and year of study. The Oxford sample only included firstyear students of similar ages, so analyses were limited to examining differences by gender. Students identifying as other than 'male' or 'female' were not included in the gender-stratified analyses because of small numbers ( $n=34 / 3013$ in the Queen's sample). Differences in proportions between strata were examined using $\chi^{2}$ tests.

Qualitative data from the Queen's and Oxford surveys were extracted from free text responses. Qualitative analysis used a framework technique. ${ }^{9}$ Participant data were interpreted and summarised. Coding comprised identification of experiences, referred to as 'themes'. As understanding increased, data were summarised and reinterpreted, new codes generated, redundant codes deleted and overlapping codes merged. Through this process a stable framework emerged that appeared increasingly likely to describe participant experience. The study team met regularly to discuss the findings and refine the emerging framework. To reduce researcher bias, the team analysing the qualitative data were not made aware of the quantitative findings until the framework had been agreed on.

The Strengthening the Reporting of Observational Studies in Epidemiology cross-sectional reporting guidelines were used in the reporting of this study. ${ }^{11}$

\section{Patient and public involvement}

The ongoing UFlourish survey is a student-informed research effort. ${ }^{6}$ Peer health educators are included at all stages of the research from design to implementation, and we will include the student perspective in the interpretation and dissemination of findings. 


\section{RESULTS}

\section{Description of the sample}

The response rate among Queen's undergraduate students was $13.5 \%(n=3452)$. The sample was broadly representative of the eligible student population by year and programme of study, full time versus part time and international versus domestic status. However, more students in the sample identified as female ( $70.1 \%$ vs $\left.57.7 \%, \chi^{2} \mathrm{p}<0.01\right)$ and were younger than 19 years old $\left(40.6 \%\right.$ vs $\left.35.0 \%, \chi^{2} \mathrm{p}<0.01\right)$. In this report, we describe the responses of 3013 students with complete data on the variables of interest (table 1). Students with missing data $(\mathrm{n}=439)$ were similar in age (mean $(\mathrm{SD})=19.6$ (3.1) vs $19.8(2.9)$, t-test $\mathrm{p}=0.34$ ) but more likely to identify as male $\left(38.5 \%\right.$ vs $\left.28.8 \%, \chi^{2} \mathrm{p}<0.001\right)$ and be international students $(21.7 \%$ vs $7.5 \%, \mathrm{p}<0.001)$. The average age of the study sample was 19.6 ( $\mathrm{SD}=2.8)$, and most students were domestic $(92.5 \%)$. Students were most likely to be preparing to begin first year (25.4\%) or finishing first year (23.9\%), and the most common programmes of study were arts, humanities, and social sciences (33.8\%), life and physical sciences (27.4\%) and engineering and applied science (20.2\%).

The response rate among the first-year Oxford student cohort was $45.0 \%(\mathrm{n}=356)$. The sample also had a higher proportion of females $(62.1 \%$ vs $54.3 \%)$ than the university database. Participants' courses included: humanities (34.6\%), mathematical, physical and life sciences (32.0\%), medical sciences $(19.9 \%)$, social sciences $(13.6 \%)$ and unknown (13.6\%). Here we describe the responses of 339 students with complete data on the Pandemic Anxiety Scale and the impact of COVID-19 items. The average age of respondents was 18.4 years old, and the majority identified as female $(61.7 \%)$. In comparison, Queen's first-year students were an average age of $18.6(\mathrm{SD}=2.4)$ years and $72.1 \%$ identified as female.

\section{Knowledge about COVID-19 and associated experiences}

Overall, Queen's students rated their knowledge of COVID-19 as good to very good $(71 \% \geq 5$ out of 7$)$. Most reported following government recommendations $(90 \%$ $\geq 5$ out of 7 ). Female students were more likely than males to report following recommendations $(91.3 \%$ vs $86.7 \%$, $\left.\chi^{2} \mathrm{p}<0.01\right)$. Knowledge and following of recommendations were lowest in students aged 18 years and younger $(68.0 \%$ and $87.3 \% \geq 5)$ and highest in students aged 21 years and older $(79.0 \%$ and $93.3 \%)$. Most students $(61.9 \%)$ reported self-isolating, defined as 'staying at home and avoiding contact with people outside of your household' (table 1). A minority reported continuing as normal $(\mathrm{n}=125(4.0 \%))$. Females were more likely to report self-isolating $\left(63.9 \%\right.$ vs $\left.57.0 \%, \chi^{2} \mathrm{p}<0.01\right)$, and males were more likely to report no change in behaviour $\left(8.0 \%\right.$ vs $\left.2.3 \%, \chi^{2} \mathrm{p}<0.01\right)$. There was no significant difference in self-isolation practices by age.

\section{COVID-19 related worries}

Responses to the Pandemic Anxiety Scale (figure 1) showed that almost all Queen's students agreed that COVID-19 is a serious issue $(93.7 \%)$. Although many students reported
Table 1 Description of the Queen's (Canadian) summer 2020 survey sample, including student levels of knowledge on COVID-19, following of recommendations, and approaches to self-isolation

\begin{tabular}{|c|c|}
\hline Age (years) & n (\%) \\
\hline$\leq 18$ & $1222(40.6)$ \\
\hline $19-20$ & $1062(35.3)$ \\
\hline$\geq 21$ & $729(24.2)$ \\
\hline \multicolumn{2}{|l|}{ Gender } \\
\hline Female & $2111(70.1)$ \\
\hline Male & $868(28.8)$ \\
\hline Other & $34(1.13)$ \\
\hline \multicolumn{2}{|l|}{ Programme of study } \\
\hline Arts, humanities and social sciences & $1019(33.8)$ \\
\hline Life and physical sciences & $824(27.4)$ \\
\hline Engineering and applied science & $607(20.2)$ \\
\hline Business & $166(5.5)$ \\
\hline Computing & $93(3.1)$ \\
\hline Nursing & $92(3.1)$ \\
\hline Health sciences & $64(2.1)$ \\
\hline Law & $74(2.5)$ \\
\hline Medicine & $74(2.5)$ \\
\hline \multicolumn{2}{|l|}{ Year of study } \\
\hline Incoming & $765(25.4)$ \\
\hline First & $721(23.9)$ \\
\hline Second & $517(17.2)$ \\
\hline Third & $536(17.8)$ \\
\hline Fourth & $369(12.3)$ \\
\hline Fifth or sixth & $105(3.5)$ \\
\hline \multicolumn{2}{|l|}{ International/domestic status } \\
\hline Domestic & $2788(92.5)$ \\
\hline International & $225(7.5)$ \\
\hline \multicolumn{2}{|l|}{ Knowledge level on COVID-19 } \\
\hline 1 (very poor) to 3 & $209(6.9)$ \\
\hline 4 & $664(22.0)$ \\
\hline 5 to 7 (very good) & $2140(71.0)$ \\
\hline \multicolumn{2}{|l|}{ Following COVID-19 recommendations } \\
\hline 1 (not at all) to 3 & $91(3.0)$ \\
\hline 4 & $203(6.7)$ \\
\hline 5 to 7 (very much so) & $2719(90.2)$ \\
\hline \multicolumn{2}{|l|}{ Approach to self-isolation } \\
\hline No change/life as usual & $125(4.0)$ \\
\hline Minor change but not isolation & $1075(34.2)$ \\
\hline Self-isolation & $1946(61.9)$ \\
\hline
\end{tabular}

concerns about catching COVID-19 (48.1\%), a greater proportion were worried about infecting others (64.0\%), or friends and family catching it $(74.9 \%)$. Few students reported being afraid to leave the house (14.7\%), and most were not worried about access to food and essential items $(87.6 \%)$. Worries about catching and transmitting 


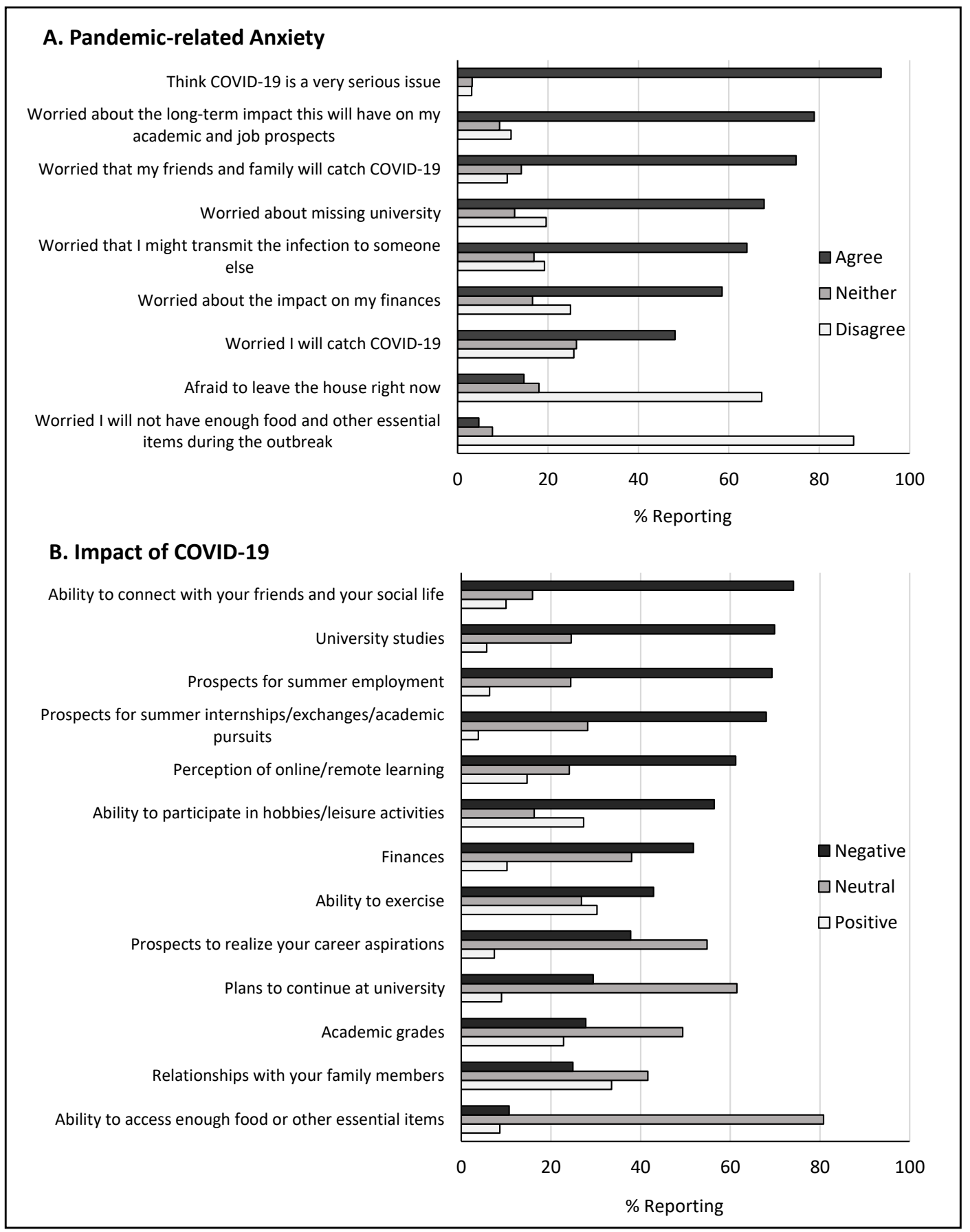

Figure 1. Queen's University undergraduate students' $(n=3,013)$ responses to the Pandemic Anxiety Scale item (Panel A), and items relating to the impact that COVID-19 and associated social distancing have had on various aspects of their lives (Panel B).

Figure 1 Queen's university students' ( $n=3013)$ responses to the Pandemic Anxiety Scale items (panel $A)$ and items relating to the impact that COVID-19 and associated social distancing have had on various aspects of their lives (panel B).

COVID-19 were greatest in females, older students and students in upper years of study (table 2). These overall trends and differences between genders were consistent with responses from Oxford students (figure 2; online supplemental table 1).
Most Queen's students reported concerns about missing university $(67.8 \%)$, with younger students most worried (age 18 years or younger $=80.4 \%$, age $19-20$ years $=72.1 \%$ and age 21 years or older $\left.=47.7 \% ; \chi^{2} \mathrm{p}<0.01\right)$. Many students reported worries about their finances $(58.4 \%)$ and long-term academic and job prospects (78.9\%). 


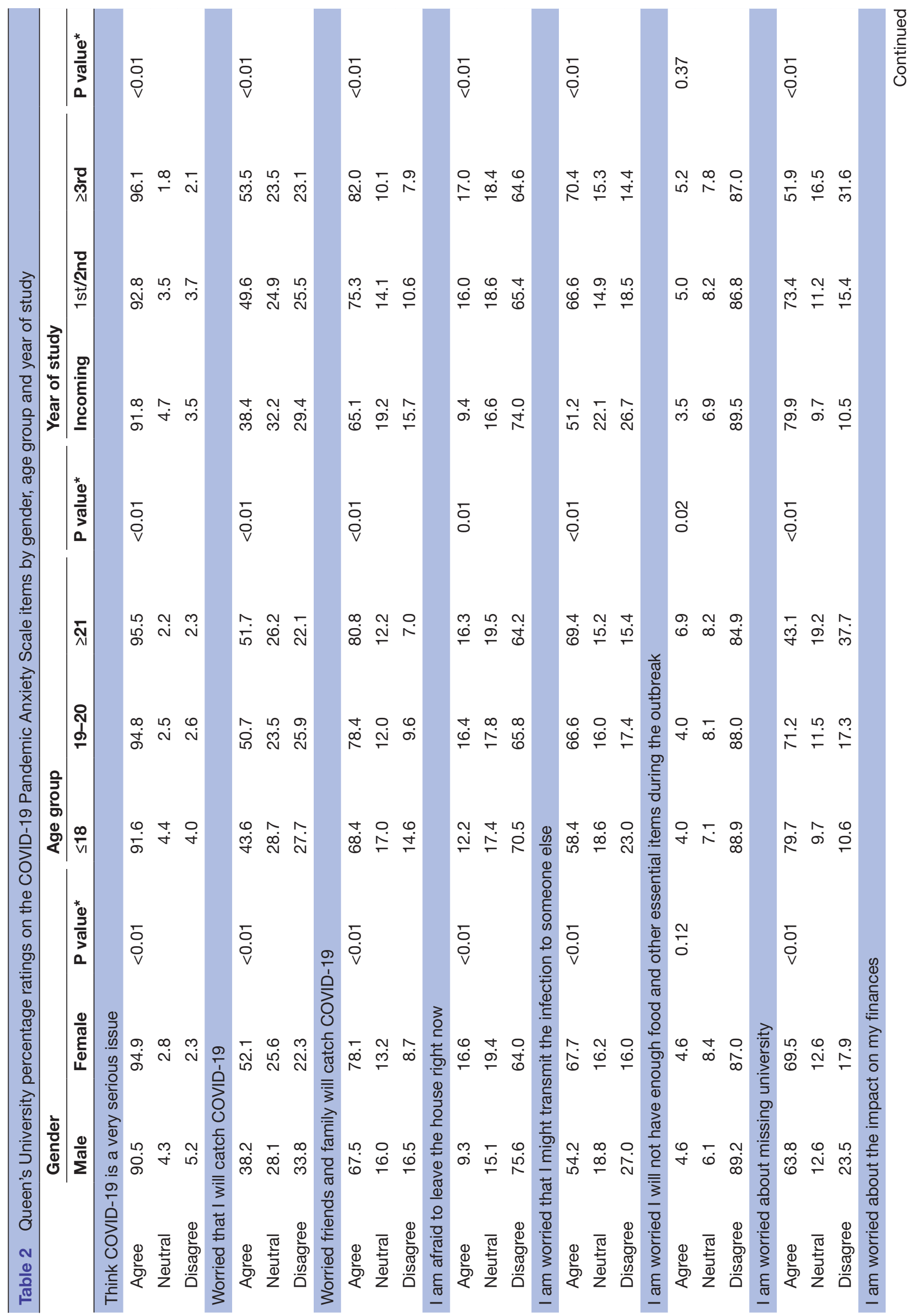




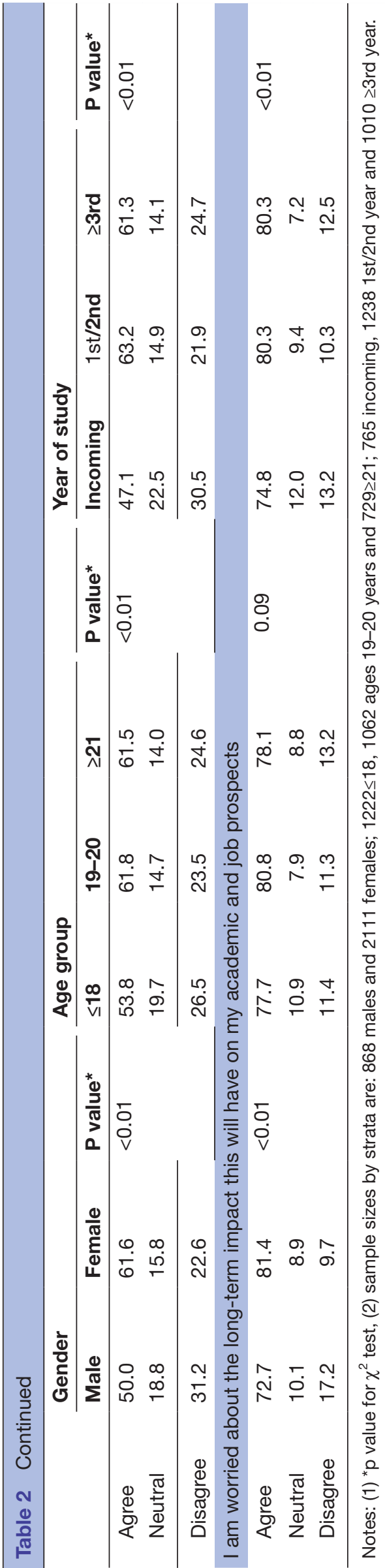

Male and incoming students were less worried about the impact on finances and long-term prospects than female and current students (table 2). Oxford student responses to the Pandemic Anxiety Scale were largely consistent with Queen's student responses, but a smaller percentage of Oxford students reported concerns about finances $(26.5 \%)$ and long-term academic and job prospects (50.4\%, figure 2). Consistent with Queen's, females at Oxford were more worried about their finances and long-term prospects (online supplemental table 1).

\section{Impact of COVID-19}

\section{Effects on university and studies}

Queen's students commonly reported that the pandemic had negatively impacted their studies (69.9\%) (figure 1 ). While most students reported neither a positive nor negative impact on their plans to continue at university $(61.5 \%)$, a notable proportion reported a negative impact $(29.4 \%)$. Incoming students were more likely to report a negative impact than current students (table 3 ). Both a positive $(22.8 \%)$ and negative $(27.8 \%)$ impact on grades was reported. Most students perceived online learning negatively $(61.2 \%)$ and reported a negative impact on their prospects for internships, exchanges and other enriched learning experiences $(68.0 \%)$. These findings were largely consistent with Oxford students' responses. However, a smaller proportion of Oxford students reported a negative impact on plans to continue at university $(14.2 \%)$ and negative perceptions of online learning (30.4\%; figure 2; online supplemental table 2).

\section{Employment and finances}

Most students at Queen's (69.3\%) and Oxford (72.6\%) reported a negative impact on their prospects for summer employment. A greater proportion of females than males reported a negative impact at Queen's $(71.4 \%$ vs $65.3 \%$, $\mathrm{p}<0.0 .01)$ and Oxford (77.5\% vs $\left.63.6 \%, \chi^{2} \mathrm{p}=0.02\right)$ (table 3, online supplemental table 2). A third of Queen's students reported a negative impact on their prospects to achieve their career aspirations $(37.8 \%)$. Students in later years of study reported a more negative impact on their career aspirations $\left(\chi^{2} \mathrm{p}<0.05\right)$. Most students reported a negative impact on their finances $(51.8 \%)$, and few reported a negative impact on their ability to access food and essentials $(10.7 \%)$. The perceived negative impact on employment prospects and finances was greatest in females, older students and students in upper years of study (table 3).

\section{Exercise, leisure and social life}

Queen's students reported both a negative $(42.9 \%)$ and positive $(30.3 \%)$ impact on their ability to exercise, but most reported a negative impact on hobbies and leisure activities $(56.4 \%)$. These findings were consistent with Oxford students (figure 2). Most students reported a negative impact on their social life $(74.0 \%)$. While many students reported neither a positive nor negative impact on relationships with family members $(41.6 \%)$, several 


\section{A. Pandemic-related Anxiety}

Think COVID-19 is a very serious issue

Worried that my friends and family will catch COVID-19

Worried about missing university

Worried that I might transmit the infection to someone else

Worried about the long-term impact this will have on my academic and job prospects

Worried I will catch COVID-19

Worried about the impact on my finances

Afraid to leave the house right now

Worried I will not have enough food and other essential items during the outbreak

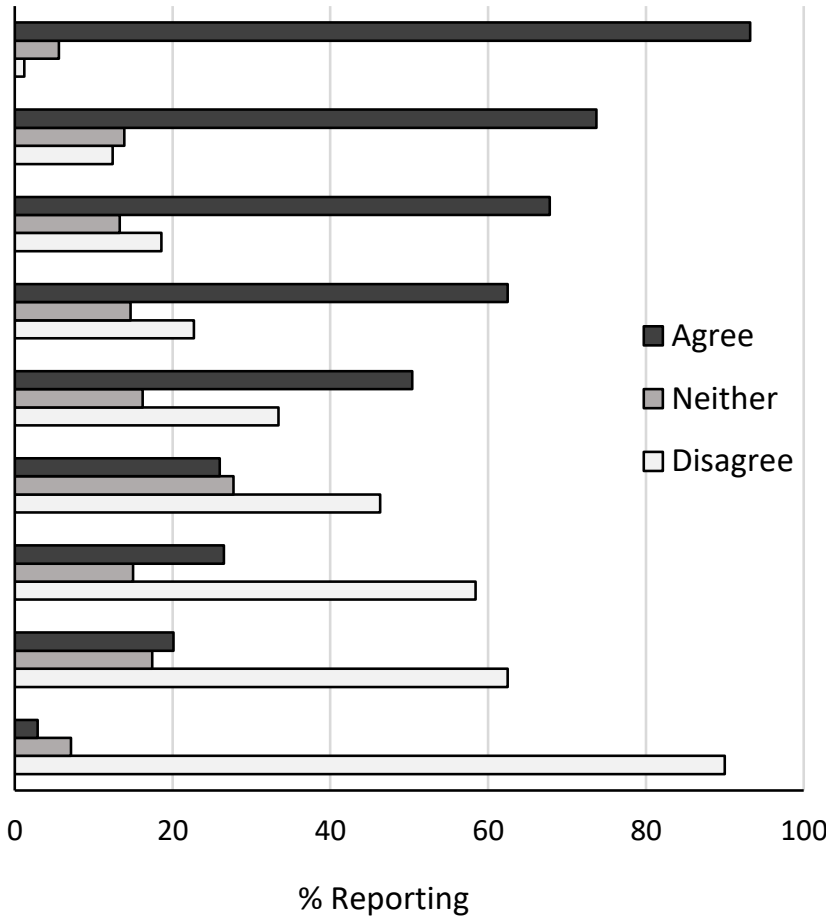

\section{B. Impact of COVID-19}

Prospects for summer employment

Ability to participate in hobbies/leisure activities

University studies

Prospects for summer internships/exchanges/academic pursuits

Ability to exercise

Perception of online/remote learning

Plans to continue at university

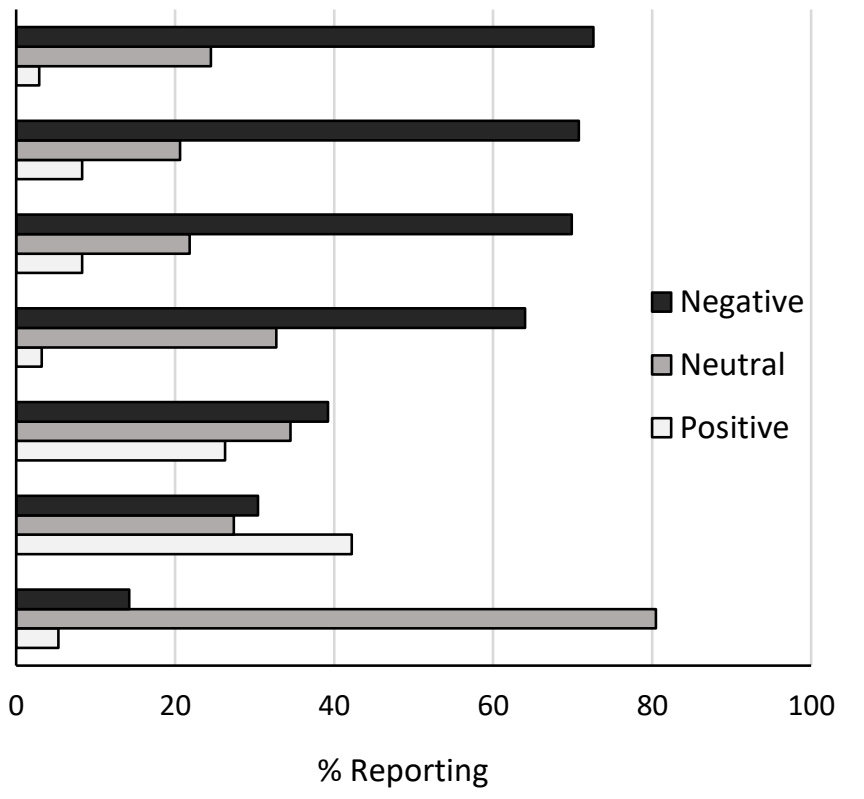

Figure 2. Oxford University first-year undergraduate students' ( $n=337$ ) responses to the Pandemic Anxiety Scale items (Panel A), and items relating to the impact that COVID-19 and associated social distancing have had on various aspects of their lives (Panel B).

Figure 2 Oxford University first-year undergraduate students' $(n=339)$ responses to the Pandemic Anxiety Scale items (panel A) and items relating to the impact that COVID-19 and associated social distancing have had on various aspects of their lives (panel B). 


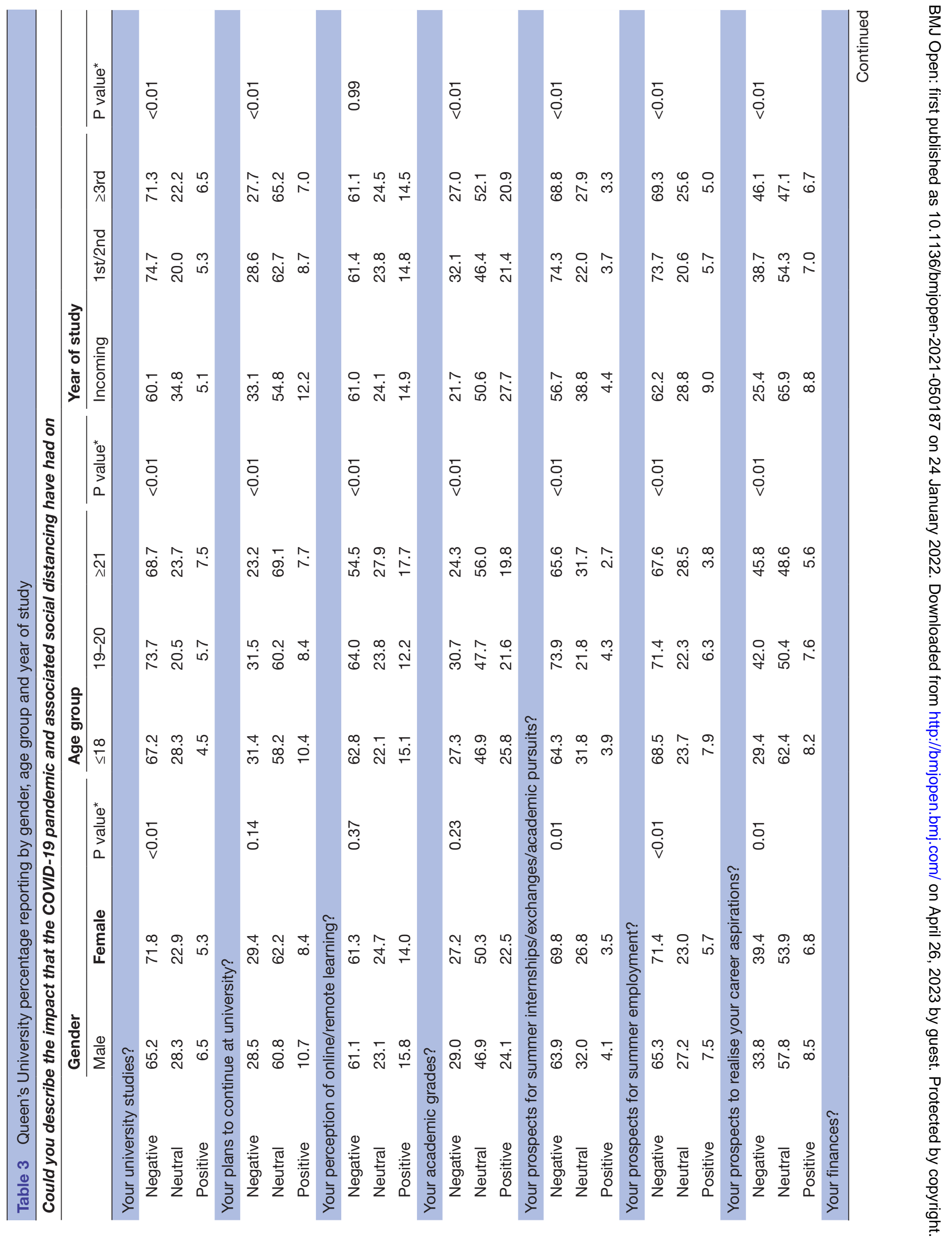




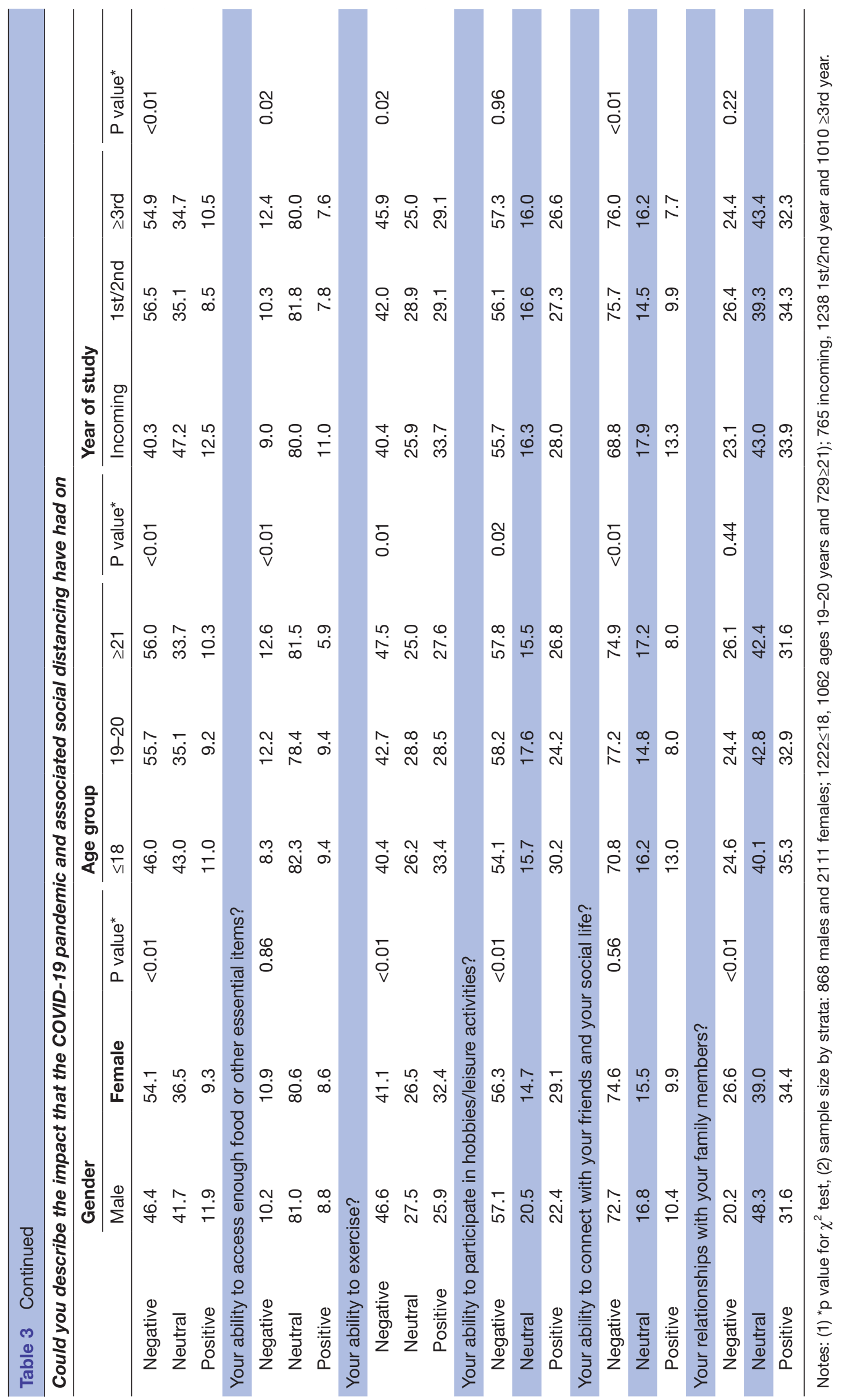


reported a negative impact $(24.9 \%)$. A negative impact on family relationships was more commonly reported by females (table 3).

\section{Receipt of mental health support}

Among Queen's students receiving mental health support $(\mathrm{n}=1256)$, most reported this was unaffected by COVID-19 (66.9\%). However, significantly more females reported their support being negatively affected than males $\left(37.4 \%\right.$ of females, $18.2 \%$ of males, $\left.\chi^{2} \mathrm{p}<0.005\right)$. There was no significant difference in the proportions of students reporting a negative impact according to age or year of study.

\section{Common pandemic impact themes: qualitative analysis}

Free-text responses to an open-ended question asking students to describe other impacts related to COVID-19 were analysed for major themes. Of these responses (Queen's $n=815$, Oxford $n=60$ ), the proportion pertaining to each theme is described further. See online supplemental material appendix A1 for representative quotes.

\section{Negative impact due to social isolation}

Many students (56.0\% Queen's, 33.3\% Oxford) described feelings of anxiety, loneliness and restlessness associated with social isolation due to loss of in-person contact with peers, friends and significant others. Many students described friends as key supports and that reduced contact worsened their well-being: 'Forced separation from part of my support system has had a negative impact on both my academics and mental health'. Students reported that isolation with roommates or family members, with whom they had already-strained relationships, increased stress and caused feelings of being trapped in a negative environment, which worsened mental health: 'Having no break from my fairly stressful home situation has not been great for my mental health'. Overall, reduced interaction with support networks and forced confinement increased stress.

\section{Challenging academic and institutional changes}

Students described challenges adapting to new learning methods $(32.1 \%$ of Queen's students, $23.3 \%$ of Oxford students). Online learning was reported as difficult or less effective than in-person instruction due to lack of quiet study spaces, blurred school and home boundaries and distance from peers: 'Getting myself into an exam or essay-writing mindset at home is much harder than I thought it would be'. Students reported difficulty coping with high work demands outside their usual surroundings, isolated from peers during a stressful time: 'I am finding it hard to keep a balanced perspective on work and assignments working at home by myself and not being around friends'. Concerns about learning experiences and future preparedness stemmed from loss of practical course components, cancellation of professional placements and reduced access to specialised facilities. The cancellation of key milestones contributed to worries about personal development and the quality of students' social experience at university. Responses concerning institutional pandemic responses were mixed, including understanding given the circumstances, and frustration with decisions regarding tuition, campus closure and a perceived lack of support.

\section{Financial challenges}

Some Queen's students (11.4\%), but no Oxford students, expressed specific financial concerns. These included frustration and anxiety regarding reduced income due to fewer career opportunities and employment termination and expenses due to student housing and university tuition fees. Reduced income combined with maintained expenses amplified financial stress.

\section{Disruptions to support services and means of coping}

A small proportion of students $(5.6 \%$ Queen's, $5.0 \%$ Oxford) described disrupted access to health and support services, including difficulties accessing medication and obtaining healthcare appointments and in-person counselling. Fear of accessing services in-person due to risk of COVID-19 exposure was reported as impeding usual care: 'Too afraid to visit hospital for routine problems'. Students described reluctance to use online services, outlining difficulties adapting to or navigating them. Reduced engagement in leisure or physical group activities usually key to managing stress and protective for mental health was reported as negatively impacting the ability to cope: 'It has removed my ability to train for my sport which was a crucial part of my weekly structure 6 days a week, and was critical in my being able to maintain my mental health and work/study productively'.

\section{DISCUSSION}

The COVID-19 pandemic has caused major disruption to university and has had far-reaching impacts on students' daily lives, well-being and perception of their future. Our study explored undergraduate student experiences and worries in the early part of the pandemic and the associated impact on their education, daily life, career prospects and mental health support. To our knowledge, this is the first study to compare the impact of the pandemic on university students across different countries. We hope that this information can be used to support students during and beyond the pandemic.

Nearly all students across both universities agreed that COVID-19 is a serious issue, but females were more likely than males to report following government recommendations and adapting their lifestyle. This may be partly due to increased anxiety among female students. Screening positive for anxiety and depression has been found to be higher in female university students and females of similar age in the general population when compared with males. ${ }^{4512}$ Moreover, females appear more susceptible to anxiety and depression surrounding COVID-19 $19^{13-15}$ and are more likely to follow COVID-19 related public health guidelines. ${ }^{16}$ In our study, a greater proportion of females 
reported worries and concerns around the pandemic than males according to the Pandemic Anxiety Scale.

Younger students were significantly more likely to report concerns about missing university than older students who were more likely to be worried about the impact on their career prospects. This may reflect different priorities: missing university is a more immediate concern for younger students who are years away from graduating. In contrast, older students may be more concerned about applying for jobs at a time where workers are being furloughed or made redundant, and employment rates are falling. ${ }^{17} 18$ This is supported by consistent concern about long-term academic and job prospects across age groups and our qualitative analysis. Queen's students, but not Oxford students, discussed concerns surrounding employment, which may reflect the older students in the Queen's sample. Overall, students at different stages of study require targeted approaches to address immediate concerns regarding future academic or career prospects.

While students expressed worries about catching COVID-19, many more were worried about infecting others or friends and family contracting it. Most students are relatively young with few comorbidities and therefore at low risk for severe COVID-19 disease but may have family members at higher risk due to their age and co-morbidities. ${ }^{19}$ This is important for decisions regarding bringing students to campus, as students may worry about returning home and potentially exposing family or friends in high-risk groups to COVID-19. The UK government introduced plans for university students to receive COVID-19 tests before returning home for Christmas, which may have allayed students' worries about exposing family members to COVID-19 but was challenging for students who tested positive and were required to isolate.

Several students expressed concern about the impact of the pandemic on their finances. A smaller proportion of Oxford students reported these concerns compared with Queen's students, which may be associated with differences in year of study and concerns about employment after graduation. Our qualitative analysis supported the contribution of mandatory continued payment for university accommodation and tuition with reduced perceived value, and loss of income to financial anxiety. ${ }^{20}$ Additionally, many students rely on their ability to work part-time or seasonally, or money from family members whose income may have been negatively affected by the pandemic. Previous studies have indicated student concern about finances during COVID-19, particularly those remaining in student residences during lockdown. ${ }^{21}$

Most students indicated that COVID-19 negatively impacted their studies, as may be expected due to online learning or course suspension. Negative perceptions of online learning suggest dissatisfaction with alternative teaching methods, which may be worsened by unchanged tuition fees and how quickly these changes were introduced. However, most Queen's students reported little impact on grades, suggesting disruption is accounted for in assessments, that students and/or professors are adapting to maintain grades or it is too early to measure the impact on academic performance. Negative perceptions of online learning were lower in the Oxford sample than in Queen's students (30.9\% vs $61.2 \%)$. This could reflect the move to online learning in Oxford taking place when the majority of first-year students would ordinarily have been sitting exams. The tutorial system at Oxford may also be more readily transferred online. Finally, online learning may have been more prevalent at Oxford prepandemic, requiring less adjustment for teaching to move fully online during the pandemic. Nearly $30 \%$ of Queen's students and 15\% of Oxford students reported a negative impact on their plans to continue at university. This may suggest students are more likely to discontinue their studies due to the pandemic, which would have significant repercussions for universities' income. Most students also reported a negative impact on their prospects for summer internships, employment, learning exchanges and other academic pursuits. Explanations include travel restrictions, workplace closures, reluctance to employ non-essential workers, social distancing restrictions and student concerns regarding COVID-19 exposure. Students' worries surrounding future academic and career prospects might be related to fewer opportunities compared with their predecessors and increased competition on graduation with less work or academic experience. Reassuringly, most students reported no impact on their ability to access food and other essentials.

Students reported both positive and negative impacts on exercise. Disruption to routines, closure of gyms or lack of university sports societies cited in our qualitative analysis may account for the negative impact. More time to exercise, availability of online classes and more space for exercise at home may account for the positive impact. Most students reported a negative impact on their participation in hobbies and leisure activities, and unsurprisingly, on their social life. The combination of these factors suggests a significant impact of COVID-19 on student mental well-being, given the importance of recreation, exercise and social connectedness to the support of mental health. ${ }^{132}$

Select populations, which may not be readily identified as requiring tailored support, reported unique challenges. Students with dependents described challenges balancing their studies and caring responsibilities due to reduced childcare services and closure of schools. International students reported inability to travel home to visit family and friends and anxiety surrounding remaining in a foreign country during a pandemic. Affordability of remaining away from home, high tuition costs and lack of financial support were concerns for these students.

Strengths of our study include providing timely, important information on a largely unknown and highly relevant topic: the impact of a global pandemic on the lives and experiences of university students. Responses from large, diverse samples of university students were used and allowed comparison between countries and institutions. Our findings build on those of previous 
studies that have focused specifically on mental health impacts ${ }^{15} 23-25$ or been limited to medical students or much smaller samples. ${ }^{26-31}$ We assessed the impact of COVID-19 using a validated Pandemic Anxiety Scale.

One study limitation relates to the low response rate in the Queen's sample, which likely reflects the timing of the survey during summer break without a preceding student engagement campaign. Nonetheless, the student sample appeared broadly representative of the Queen's undergraduate population in terms of demographics and programme of study. Second, the Oxford data pertain only to first-year students and served as a descriptive exploratory analysis to compliment the Canadian data. Differing pandemic responses may have impacted comparability across the universities, but the overall consistency of the findings strengthens our conclusions and their generalisability. The increased surveying of younger Oxford students may be more informative for higher education policies, as these students are more likely to be at university when these policies are enacted. In this analysis, students at both universities were surveyed early in the pandemic, and worries and impacts may change over the course of the pandemic. Therefore, we will repeatedly survey students at both universities to better understand student concerns and the impact of the pandemic on student experiences and well-being over time. We hope that this information will help to inform universities regarding how best to address student learning and wellbeing needs.

\section{CONCLUSION}

The COVID-19 pandemic has had wide-ranging impacts on university students' experience and mental health. Our findings support that undergraduate students have concerns regarding disruptions to university studies, the inadequacies of online learning as a substitute for in-person learning and their finances and future academic and career prospects. A concerning number of students reported the possibility of discontinuing their studies due to the pandemic. Many students reported negative impacts of COVID-19 on protective factors for well-being, including socialising, exercise, hobbies and leisure activities, family relationships and mental health support. Higher education institutions must prepare to address students' concerns in the short term during the pandemic and provide ongoing support for students in the aftermath of COVID-19 as the long-term impacts become apparent.

\footnotetext{
Author affiliations

${ }^{1}$ Oxford Medical School, University of Oxford Medical Sciences Division, Oxford, UK ${ }^{2}$ Department of Public Health Sciences, Queen's University, Kingston, Ontario, Canada

${ }^{3}$ Department of Psychiatry, University of Oxford, Oxford, UK

${ }^{4}$ Oxford Health NHS Foundation Trust, Warneford Hospital, Oxford, UK

${ }^{5}$ Department of Pharmacology and Toxicology, University of Toronto, Toronto,

Ontario, Canada

${ }^{6}$ Faculty of Health Sciences, Queen's University, Kingston, Ontario, Canada
}

${ }^{7}$ Department of Psychology, Queen's University, Kingston, Ontario, Canada ${ }^{8}$ Department of Psychiatry, Queen's University, Kingston, Ontario, Canada

Acknowledgements We acknowledge the important role of the student volunteers who worked on the Queen's Student Engagement campaign including Mimi Li and Anjalika Khan. KES is supported by the NIHR Oxford Health Biomedical Research Centre (grant BRC-1215-20005).

Contributors ACD developed the protocol in collaboration with colleagues including KES and students including DR, NK and SC. DR led the student engagement campaign at Queen's and SC and ACD the survey launch, while CK supervised by ACD and KES led the engagement and survey launch at Oxford. JAA, NK and ACD led the quantitative analysis, while KES, AB, JB and DR the qualitative analysis. All named authors contributed to the writing and reviewed the final manuscript. ACD is the guarantor responsible for the overall content.

Funding This study was funded by an operating grant from the Canadian Institutes of Health Research (CIHR) PJT 165597.

Disclaimer The views expressed are those of the authors and not necessarily those of the UK National Health Service, the National Institute for Health Research or the UK Department of Health.

Competing interests KES is supported by the National Institute for Health Research Oxford Health Biomedical Research Centre (grant BRC-1215-20005).

Patient consent for publication Not applicable.

Ethics approval Ethical approval was obtained from the Central University Research Ethics Committee in Oxford (R60998 - RE001) and the Queens University Health Sciences and Affiliated Teaching Hospitals Research Ethics Board (HSREB) in Canada (PSIY-669-19). Participants gave informed consent as part of the survey. Participants gave informed consent to participate in the study before taking part.

Provenance and peer review Not commissioned; internally peer reviewed.

Data availability statement Data are available on reasonable request. Deidentified raw data are available on reasonable request to the corresponding author.

Supplemental material This content has been supplied by the author(s). It has not been vetted by BMJ Publishing Group Limited (BMJ) and may not have been peer-reviewed. Any opinions or recommendations discussed are solely those of the author(s) and are not endorsed by BMJ. BMJ disclaims all liability and responsibility arising from any reliance placed on the content. Where the content includes any translated material, BMJ does not warrant the accuracy and reliability of the translations (including but not limited to local regulations, clinical guidelines, terminology, drug names and drug dosages), and is not responsible for any error and/or omissions arising from translation and adaptation or otherwise.

Open access This is an open access article distributed in accordance with the Creative Commons Attribution Non Commercial (CC BY-NC 4.0) license, which permits others to distribute, remix, adapt, build upon this work non-commercially, and license their derivative works on different terms, provided the original work is properly cited, appropriate credit is given, any changes made indicated, and the use is non-commercial. See: http://creativecommons.org/licenses/by-nc/4.0/.

\section{ORCID iDs}

Jennifer A Appleby http://orcid.org/0000-0002-4862-052X

Nathan King http://orcid.org/0000-0003-4664-5456

Daniel Rivera http://orcid.org/0000-0001-5343-525X

Anne C Duffy http://orcid.org/0000-0002-5895-075X

\section{REFERENCES}

1 Adhikari SP, Meng S, Wu Y-J, et al. Epidemiology, causes, clinical manifestation and diagnosis, prevention and control of coronavirus disease (COVID-19) during the early outbreak period: a scoping review. Infect Dis Poverty 2020;9:29.

2 Pfefferbaum B, North CS. Mental health and the Covid-19 pandemic. N Engl J Med Overseas Ed 2020;383:510-2.

3 Crawford J, Butler-Henderson K, Rudolph J. COVID-19: 20 countries' higher education intra-period digital pedagogy responses. Journal of Applied Learning \& Teaching 2020;3.

4 King N, Pickett W, McNevin SH, et al. Mental health need of students at entry to university: baseline findings from the U-Flourish student well-being and academic success study. Early Interv Psychiatry 2021;15:286-95. 
5 Duffy A, Keown-Stoneman C, Goodday S, et al. Predictors of mental health and academic outcomes in first-year university students: identifying prevention and early-intervention targets. BJPsych Open 2020;6:e46.

6 Goodday SM, Rivera D, Foran H, et al. U-Flourish university students well-being and academic success longitudinal study: a study protocol. BMJ Open 2019;9:e029854.

7 McElroy E, Patalay P, Moltrecht B, et al. Demographic and health factors associated with pandemic anxiety in the context of COVID-19. Br J Health Psychol 2020;25:934-44.

8 RStudio Team. RStudio: integrated development for R RStudio, 2020 Available: http://wwwrstudiocom/

9 Ritchie J, Spencer L. Qualitative data analysis for applied policy research by Jane Ritchie and Liz Spencer. In: Analysing qualitative data'. London: Routledge, 1994: 173-94.

10 Gale NK, Heath G, Cameron E, et al. Using the framework method for the analysis of qualitative data in multi-disciplinary health research. BMC Med Res Methodol 2013;13:117.

11 von Elm E, Altman DG, Egger M, et al. Strengthening the reporting of observational studies in epidemiology (STROBE) statement: guidelines for reporting observational studies. BMJ 2007;335:806-8.

12 McManus S, Bebbington PE, Jenkins R, et al. Data resource profile: adult psychiatric morbidity survey (APMS). Int J Epidemiol 2020;49:361-2.

13 Xiong J, Lipsitz O, Nasri F, et al. Impact of COVID-19 pandemic on mental health in the general population: a systematic review. $J$ Affect Disord 2020;277:55-64.

14 Smith L, Jacob L, Yakkundi A, et al. Correlates of symptoms of anxiety and depression and mental wellbeing associated with COVID-19: a cross-sectional study of UK-based respondents. Psychiatry Res 2020;291:113138.

15 Elmer T, Mepham K, Stadtfeld C. Students under lockdown: comparisons of students' social networks and mental health before and during the COVID-19 crisis in Switzerland. PLoS One 2020;15:e0236337

16 Guzek D, Skolmowska D, Głąbska D. Analysis of Gender-Dependent Personal Protective Behaviors in a National Sample: Polish Adolescents' COVID-19 Experience (PLACE-19) Study. Int J Environ Res Public Health 2020;17:5770.

17 Statistics Canada. Canadian economic Dashboard and COVID-19, 2020. Available: https://www150statcangcca/n1/pub/71-607-x/71607-x2020009-enghtm [Accessed 31st Oct 2020].

18 Office for national statistics 2020 coronavirus (COVID-19) roundup: economy, business and jobs, 2020. Available: https://wwwonsgovuk/ peoplepopulationandcommunity/healthandsocialcare/ conditionsanddiseases/articles/coronaviruscovid19roundupeconomy businessandjobs/2020-07-02\#youngperson [Accessed 31 Oct 2020].

19 Clift AK, Coupland $\mathrm{CAC}$, Keogh $\mathrm{RH}$, et al. Living risk prediction algorithm (QCOVID) for risk of hospital admission and mortality from coronavirus 19 in adults: national derivation and validation cohort study. BMJ 2020;371:m3731.

20 Office for national statistics 2020 labour market overview, UK, 2020. Available: https://wwwonsgovuk/employmentandlabourmarket/ peopleinwork/employmentandemployeetypes/bulletins/ uklabourmarket/october2020 [Accessed 31 Oct 2020].

21 Husky MM, Kovess-Masfety V, Swendsen JD. Stress and anxiety among university students in France during Covid-19 mandatory confinement. Compr Psychiatry 2020;102:152191-191.

22 Rastegar Kazerooni A, Amini M, Tabari P, et al. Peer mentoring for medical students during the COVID-19 pandemic via a social media platform. Med Educ 2020;54:762-3.

23 Copeland WE, McGinnis E, Bai Y, et al. Impact of COVID-19 pandemic on college student mental health and wellness. J Am Acad Child Adolesc Psychiatry 2021;60:134-41.

24 Essadek A, Rabeyron T. Mental health of French students during the Covid-19 pandemic. J Affect Disord 2020;277:392-3.

25 Wathelet M, Duhem S, Vaiva G, et al. Factors associated with mental health disorders among university students in France confined during the COVID-19 pandemic. JAMA Netw Open 2020;3:e2025591.

26 Alsoufi A, Alsuyihili A, Msherghi A, et al. Impact of the COVID-19 pandemic on medical education: medical students' knowledge, attitudes, and practices regarding electronic learning. PLOS One 2020;15:e0242905

27 Byrnes YM, Civantos AM, Go BC, et al. Effect of the COVID-19 pandemic on medical student career perceptions: a national survey study. Med Educ Online 2020;25:1798088.

28 Choi B, Jegatheeswaran L, Minocha A, et al. The impact of the COVID-19 pandemic on final year medical students in the United Kingdom: a national survey. BMC Med Educ 2020;20:206.

29 Kecojevic A, Basch $\mathrm{CH}$, Sullivan $\mathrm{M}$, et al. The impact of the COVID-19 epidemic on mental health of undergraduate students in New Jersey, cross-sectional study. PLoS One 2020;15:e0239696.

30 Lyons Z, Wilcox H, Leung L, et al. COVID-19 and the mental wellbeing of Australian medical students: impact, concerns and coping strategies used. Australas Psychiatry 2020;28:649-52.

31 Son C, Hegde S, Smith A, et al. Effects of COVID-19 on college students' mental health in the United States: interview survey study. J Med Internet Res 2020;22:e21279. 